\title{
Online Experimentation Forum
}

\author{
http://dx.doi.org/10.3991/ijoe.v12i04.5782 \\ A. Cardoso ${ }^{1}$, M.T. Restivo ${ }^{2}$, H. Guerra ${ }^{3}$ and L.M. Gomes ${ }^{3}$ \\ ${ }^{1}$ University of Coimbra, Coimbra, Portugal \\ ${ }^{2}$ University of Porto, Porto, Portugal \\ ${ }^{3}$ Algoritmi Research Centre \& University of the Azores, Ponta Delgada, Portugal
}

\begin{abstract}
Online experimentation is based on emerging technologies for remote and virtual experimentation also aided and complemented by other online applications based in virtual reality, augmented reality, sensorial devices, potentiated by additional tools like live videos, interactive videos and serious games available through web platforms, which promote user immersion in virtual environments recreating the reality. This Special Issue collects a set of selected short papers describing 22 different works exploring online experimentation, demonstrated during the Exhibition Sessions of the $3^{\text {rd }}$ edition of the Experiment@International Conference - exp.at'15.
\end{abstract}

Index Terms-Online experimentation, remote sensing, remote monitoring, virtual reality, augmented reality.

\section{INTRODUCTION}

This Special Issue of the International Journal of Online Engineering aims to present a diversified set of short papers based on some of the Demos presented in the Exhibition Sessions of the $3^{\text {rd }}$ Experiment@International Conference - exp.at' 15 and to clarify the concept of Online Experimentation.

Experiment@, is a biannual conference that aims to foster the expansion and dissemination of Online Experimentation. It includes remote and virtual experimentation as identifiable and accessible objects and their virtual representations in the Internet of Things (IoT) framework [1].

"Online Experimentation (OE) comprises remote and 2D and 3D virtual experiments also aided and complemented by other online applications based in virtual reality, augmented reality, sensorial devices, and additional tools as live videos, interactive videos and serious games which promote user immersion in virtual environments recreating the real experience" [2].

OE resources involve experiments of different types (remote, virtual or hybrid) which can be considered as IoT resources, delivering to the user visual and sound information and data over a network, to other devices or servers, or allowing remote actuation upon physical instruments or their virtual representation [3]. In a context where everything (people, processes, data and "things") is connected by the Internet, in the so called Internet of Everything (IoE), making a relevant and valuable network [4], it is understandable that $\mathrm{OE}$ has been increasing its relevance in a persistent growth in all areas, namely in the engineering area.

The contributions of this Special Issue are effective examples of the use of emerging technologies to design, develop and build a wide range of experiments and make them available online, integrating the universe of the IoT, spreading its application in different fields, including research, industry, medicine, life sciences, education and training.

\section{EXP.AT'15 \& EXHIBITION SESSIONS}

exp.at' 15 reached its objectives bringing together engineers, researchers and professionals from different areas. It also offered an environment with examples of excellent laboratories (e.g., the Centre for Volcanology and Geological Risks Assessment (CVARG), of the University of the Azores, and the Centre for Information and Seism volcanic Surveillance of the Azores, (CIVISA)) or the remote controlled Pico Vermelho Geothermal Power Plant, and a forum to promote discussion and collaboration between academics, researchers and people from industry and institutions of several areas.

exp.at' 15 was attended by 120 participants from 21 countries on five continents, from higher education and research institutions, companies and other national and international institutions. The pre-conference activities hosted two thematic workshops, meetings of international projects (Go-Lab, NeReLa, VISIR) and the IEEE Standardization committee P187 as well as technical visits to different labs, infra-structures and scientific centers located in the São Miguel island (Azores, Portugal).

The Conference offered 45 presentations of scientific works in 11 parallel sessions plus 2 sessions within the Special Track "Online Experimentation in Science and Engineering Education" (OEEE'15). Thirteen invited communications were spread by two Plenary Sessions. Two Exhibition Sessions housed 42 Online Demo Resources. The Conference also offered three Keynotes:

- "From local natural events to global catastrophes: new challenges for risk mitigation" by João Luís Gaspar, Professor and Rector of the University of the Azores (Portugal) and researcher at the CVARG/CIVISA Laboratory;

- "Know-How and Know-Why: Lab-Created Learning" by Susan Zvacek, Associate Provost for the Advancement of Teaching and Learning at the University of Denver (USA);

- "Living and Working with the Internet of Things", by Mark Schulz, Professor and Researcher at the University of Queensland (Australia).

Looking for promoting research in OE and cooperation with industry and relevant institutions in this field, exp.at'15 included the Plenary Session I "Online Experimentation as a Tool for Research" at the Regional Laboratory of Civil Engineering (LREC) of the Azores with the following communications: 
- "Dynamic Monitoring of Civil Engineering Structures" by Elsa Caetano (University of Porto, Portugal);

- "Weighing in Motion and Wheel Defect Detection of Rolling Stock" by Rodolfo Martins (Evoleo Technologies, Portugal);

- "3D Atmosphere Column Evaluation and Clouds Tomography at Eastern North Atlantic" by Eduardo Azevedo (University of the Azores, Portugal);

- “Off-line/on-line? Why not both?" by Miguel Motos (Ingevideo, Spain);

- "IAOE - The International Association of Online Engineering" by Doru Ursutiu (IAOE President);

- "IEEE Education Society" by Manuel Castro (Jr. Past President of IEEE Education Society).

The Plenary Session II, "Online Experimentation as a Tool for Research and Education" in a singular environment: the Theater of Ribeira Grande (São Miguel island, Azores), with the following contributions:

- "Ocean Observing/Monitoring Systems: Some past and present applications in Azores waters" by Mário Pinho (University of the Azores, Portugal);

- "The Use of Surveillance Data in Augmented Reality System to Assist Control Tower Operations", by Eduardo Ferreira (Member of Air Traffic Safety Electronics Personnel Team, Portugal);

- "Skills Development for the Internet of Everything" by Nuno Guarda (CISCO, UK);

- "Go-Lab Project" by Denis Gillet (École Polytechnique Fédérale de Lausanne, Switzerland, Go-Lab Project Coordinator);

- "NeReLa Project" by Radojka Krneta (University of Kragujevac, Serbia, NeReLa Project Coordinator);

- "PELARS Project" by Anna Friesel (Technical University of Denmark);

- "EDOC Project" by Mario Bochicchio (University of Salento, Italy, EDOC Project Leader).

In order to involve STEM courses students, exp.at'15 offered the possibility to students from the University of the Azores to participate in its Exhibition Sessions, continuing the tradition of past editions and pursuing its dissemination goals. Organizations representatives and exp.at' 15 participants contributed enthusiastically for the Exhibition Sessions atmosphere. Some of the 42 presented Demos have been reworked in a short paper format and are included in this Special Issue.

Continuing the tradition of the past Exhibition Sessions, Demos were evaluated by a panel of four experts, Katarina Zakova, Manuel Castro, Mario Bochicchio and Mark Schulz, based in the following criteria:

- suitability of topic to online experimentation;

- quality of demonstration;

- technical correctness and completeness of solutions;

- online availability and possibility of reuse.

The final results awarded the two best demos, one being from education side and the other within any of the medical/industrial/research areas. Two other demos were also awarded with honorable mentions considering the referred classification.
The awarded Best Demos are:

- "Archimedes Remote Lab"

- Javier García-Zubía, Ignacio Angulo, G. MartínezPieper, D. López de Ipiña, Unai Hernández, Pablo Orduna, Olga Dziabenko, Luis Rodríguez-Gil;

- "Dynamic Monitoring of Lively Footbridges"

- Elsa Caetano, Álvaro Cunha, Carlos Moutinho, Weihua Hu.

Due to the high level of works, two Honorable Mentions were also attributed:

- "Labicom Labs: RLL, GNSS, Oscilloscope and Generator Remote and Virtual Labs", Igor Titov, Alexander Glotov, Igor Vlasov, Jakov Mikolnikov;

- "Demonstration of the Influence of Human Emotions in Physiological Signals", Bruno Patrão, João Seabra, Samuel Pedro, Paulo Menezes.

Fig. 1 and Fig. 2 show pictures from the Exhibition Sessions.
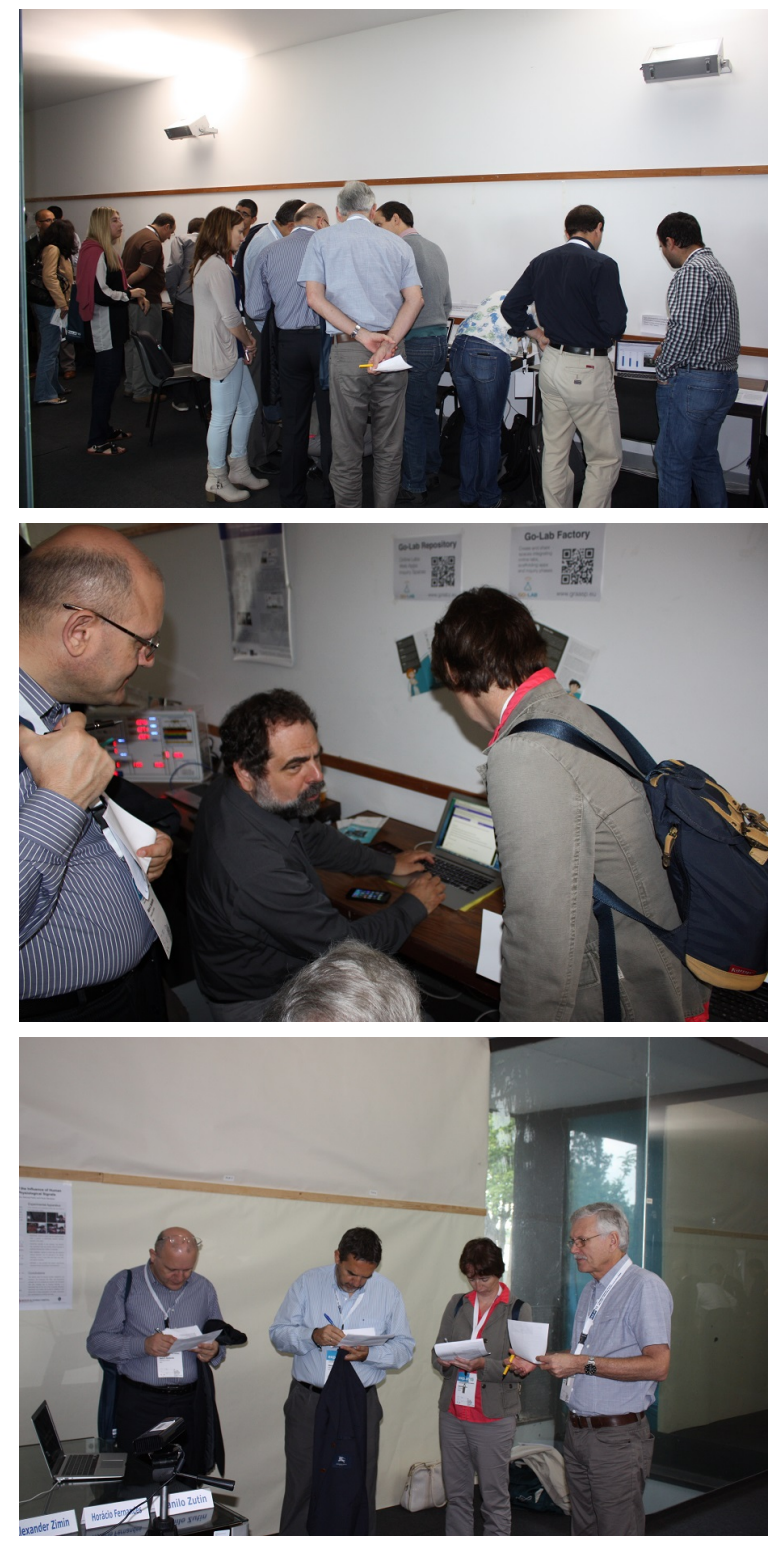

Figure 1. Authors and jury interaction during Exhibition Sessions within expat' 15 . 

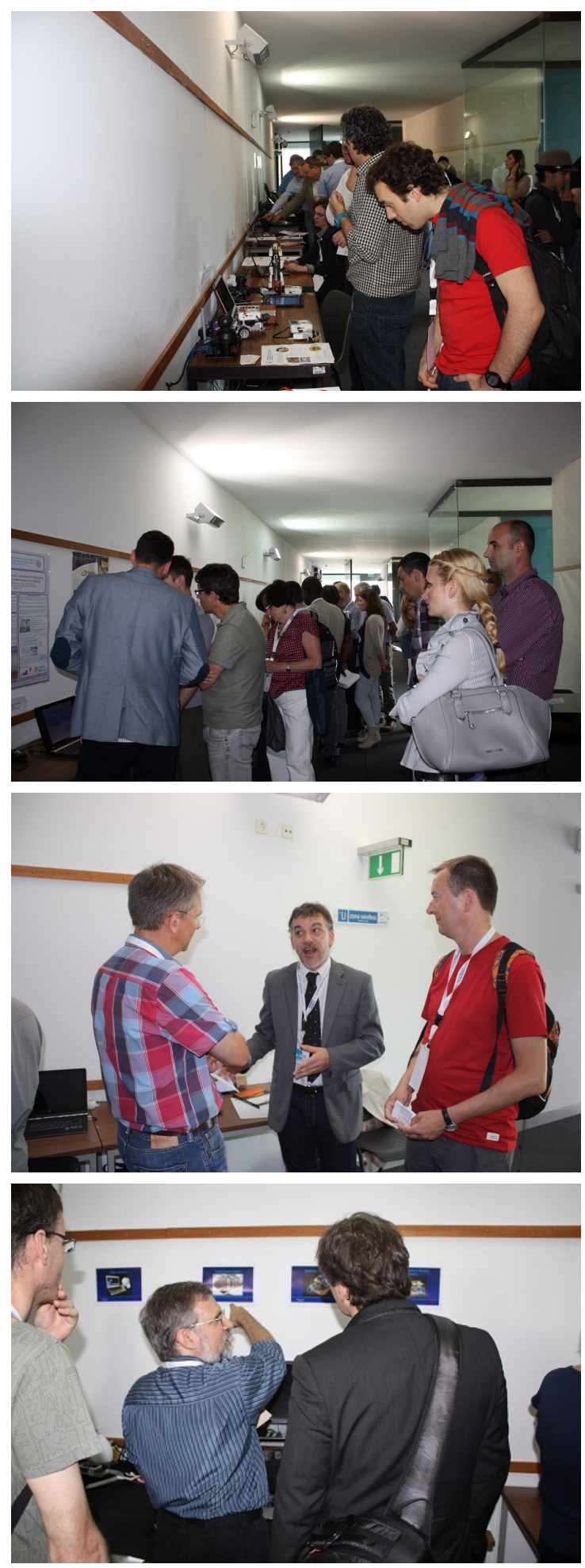

Figure 2. Authors and participants interaction during Exhibition Sessions within expat'15.

During the Exhibition Sessions authors had the opportunity to demonstrate and explain to the participants the main features of its resources. The presented demos based in different used technologies were examples of online experimentation in a wide range of application areas.

\section{FINAL REMARKS}

exp.at'15 Exhibition Sessions continued the tradition of a very successful event within this Conference. However exp.at'15 success benefited of the support of different institutions and of many institutional and individual people that made possible a comprehensive and attractive program in a unique region, to which the organizers wish to express their deep gratefulness. A word of gratitude is also due to the Exhibition Sessions Chairs, Alexander Zimin, Danilo Zutin and Horácio Fernandes, and finally, last but not least, to all Demos' reviewers - Alexander Zimin, Ana Pavani, A. Augusto Sousa, Danilo Zutin, Gustavo Alves, Horácio Fernandes, Igor Titov, Javier Garcia Zubia, José Couto Marques, Juarez Silva, Katarina Zakova, Mario Bochicchio, Radojka Krneta, Roderval Marcelino and Vilson Gruber.

For the success of Exhibition Sessions the valuable support of the exp.at'15 main sponsors had been also important - the University of Porto, the University of Coimbra and the University of the Azores, the Technical Sponsors - IEEE, SPEE, IGIP, IAOE, iJOE, iJET, iJIM, Emerald, Go-Lab, NeReLa and Cisco, and all other sponsors Governo dos Açores, Secretaria Regional do Mar, Ciência e Tecnologia and Secretaria Regional do Turismo e Transportes do Governo dos Açores, Fundação para a Ciência e Tecnologia (FCT), Câmara Municipal de Ponta Delgada, Câmara Municipal da Ribeira Grande, Coliseu Micaelense, Laboratório Regional de Engenharia Civil, expolab - Centro de Ciência Viva, SATA, Ordem dos Engenheiros, RS Portugal, António Moutinho Lda, Mixtrónica, HFA, INEGI, EDA, Controlar, Cargobase, Empresa de Transportes Courense, Critical Software, iTGrow, Ingevideo, Caixa Leasing e Factoring, Gorreana, Queijada do Morgado, Promineral, A Mulher de Capote, Quintal dos Açores, and, finally, to Caminhos \& Cenários - Turismo e Eventos Unipessoal Lda.

\section{REFERENCES}

[1] Proceedings of $3^{\text {rd }}$ Experiment@International Conference, June 13, 2015, Ponta Delgada, Azores, Portugal.

[2] M.T. Restivo and A. Cardoso, "Exploring Online Experimentation", Guest Editorial of the Special Issue: exp.at'13, International Journal of Online Engineering (iJOE), Vol. 9, pp. 4-6, 2013. http://dx.doi.org/10.3991/ijoe.v9iS8.3448

[3] M.T. Restivo, A. Cardoso and A.M. Lopes, Preface of the Book "Online Experimentation: Emerging Technologies and IoT", IFSA - International Frequency Sensor Association Publishing, 2015.

[4] http://www.cisco.com/web/about/ac79/innov/IoE.html [Accessed on $30 / 12 / 2015]$.

\section{AUTHORS}

A. Cardoso is with the Dep. of Informatics Engineering of the University of Coimbra, DEI, Polo II - UC, 3030290 Coimbra, Portugal (alberto@dei.uc.pt).

M. Teresa Restivo is with UISPA research unit of LAETA/INEGI and with the Faculty of Engineering of University of Porto, Porto, Portugal (trestivo@fe.up.pt).

H. Guerra and L.M. Gomes are with Algoritmi Research Centre and the Dep. of Mathematics (Informatics Section) of the University of the Azores, Rua da Mãe de Deus, 9501-855 Ponta Delgada, Portugal (helia.mg.guerra@uac.pt and luis.mp.gomes@uac.pt).

The authors wish to thank Direção Regional da Ciência e Tecnologia (Secretaria Regional do Mar, Ciência e Tecnologia - Região Autónoma dos Açores) for supporting this contribution on online experimentation. Submitted, 30 December 2015. Published as resubmitted by the authors 04 february 2016. 